\title{
Potential Hazard Map for Disaster Prevention Using GIS-Based Linear Combination Approach and Analytic Hierarchy Method
}

\author{
Szu-Hsien Peng1, Meng-Ju Shieh ${ }^{1}$, Shih-Yi Fan ${ }^{2}$ \\ ${ }^{1}$ Department of Spatial Design, Chienkuo Technology University, Changhua City, Chinese Taipei \\ ${ }^{2}$ Economic Affairs Department, Changhua County Government, Changhua City, Chinese Taipei \\ Email: shpeng@cc.ctu.edu.tw
}

Received August 1, 2012; revised August 31, 2012; accepted September 28, 2012

\begin{abstract}
In recent years, global warming has gradually become obvious, thus created the climate change. Typhoon Morakot attacked Taiwan and brought heavy rainfall in August, 2009. In mountainous areas including Central and South Taiwan, the flood and debris flow disasters were induced by the typhoon. In this study, Changhua City is selected as the research region and the Delphi method is employed to interview experts and establish comprehensive evaluation criteria for assessing the evacuation plan on disaster areas. The concept is to combine the landslide potential analysis by geographic information systems with the flood or debris flow maps into the potential hazard map. Meanwhile, analytic hierarchy method (AHP) is comprehensively carried on the expert questionnaire survey for the potential hazard map of the compound disaster states. It should be useful for the local government and native people in the future.
\end{abstract}

Keywords: Geographic Information Systems; Potential Hazard Map; Analytic Hierarchy Method (AHP)

\section{Introduction}

With the gradually apparent global warming causing the climate change, Typhoon Morakot attacked the central and southern Taiwan in August 2009 and resulted in serious disasters. With the unusual route of Typhoon Morakot, its long stay in Taiwan, and the effect of southwest monsoon, the heavy rainfall caused major disasters. According to the estimation of Water Resources Agency [1], the rainfall reached the world extreme record. Besides, regarding the historical rainfall in one day, Typhoon Morakot was also ranked at the top. Climate change resulted from global warming is expected to result in similar events in the future. The entire Taiwan experienced such heavy rainfall during the attack of Typhoon Morakot that various disasters were caused by long-period, high-intensity, and wide-spread rainfall, such as floods, debris flows, landslides, and landslide-dammed lakes $[2,3]$.

In face of the reflection on natural disasters and disaster relief operations as well as in corresponding to the change of climate and natural environment, a lot of thinking models should be adjusted. How to arrange secure and prompt evacuation points has therefore become one of the primary research issues. A multi-criteria evaluation (MCE) method can usually deal with the available information concerning choice-possibilities in regional planning. Meanwhile, weighted linear combination (WLC) is one of the widely employed MCE methods for land suitability analysis [4]. Besides, flood risk and flood damage estimates are studied by spatial multi-criteria analysis, geographic information systems (GIS) and mathematical models [5-8]. The previous researches offered the knowledge of flood risk in different spatial locations for developing effective flood mitigation strategy and damage estimation for a watershed or regional planning.

Therefore, with analytic hierarchy process (AHP) to proceed expert questionnaire survey and to analyze the weight of various factors, this study aims to collect map data related to landslide, flood potential analysis, debris flow potential areas, and land use in Changhua City. The map overlaying analysis in geographic information systems (GIS) is utilized for establishing the compound potential hazard map. The research outcomes are expected to provide the relevant sectors evaluating the original hideout points, evacuation routes or evacuation system, and disaster prevention.

\section{Research Method}

With linear combination method to evaluate the compound potential hazard map, the combination would give 
each factor a relative weight when evaluating the appropriateness of factor attribute toward the evaluated subject. Analytic hierarchy process (AHP) was applied to designing the expert questionnaire for the weights of factors. With pair wise comparison to estimate the eigenvector for the weight of the criteria [9], the weight was directly evaluated by the map overlaying analysis in geographic information systems (GIS). AHP and the map overlaying in GIS are briefly described as follows.

\subsection{Analytic Hierarchy Process (AHP)}

Analytic hierarchy process (AHP) could master the factors in decision-making with hierarchic structures. The nominal scale is applied to pair comparison among factors so that the uncountable human feelings and preference are quantified and the pair comparison matrix is established for the eigenvector for the priority. It presents the characteristics of structure, complex scale, rational pair comparison, and integrating opinions from different decision-makers with the weighted average value. Since Saaty first proposed AHP in 1971 and published the introduction in 1980, the book was revised in 1986 and AHP has been widely applied to decision analysis practices.

In order to obtain the relative importance of factors, they are paired for comparison. According to the suggestion of Saaty of nine-scale (Table 1), it could be designed a paired questionnaire. When there are $n$ criteria, $n(n-$ 1)/2 times pair comparisons are required, Table 2 . The compared results are established paired positive reciprocal matrices, where $a_{i j}$ is the compared value between $i$ and $j$, and the main diagonal is the self-comparison of factors that the value appears 1 . The compared questionnaire becomes the value on the top-right of the diagonal in the matrix, while the value on the bottom-left of the diagonal is the reciprocal, i.e., $a_{j i}=1 / a_{i j}$. When pair evaluation is preceded, the entire geometric mean is regarded as the representative. The pair matrix $\mathbf{A}$ is shown as below:

$\mathbf{A}=\left[\begin{array}{cccc}1 & a_{12} & \ldots & a_{1 n} \\ a_{21} & 1 & \ldots & a_{2 n} \\ \vdots & \vdots & \ldots & \vdots \\ a_{n 1} & a_{n 2} & \ldots & 1\end{array}\right]=\left[\begin{array}{cccc}1 & a_{12} & \ldots & a_{1 n} \\ 1 / a_{12} & 1 & \ldots & a_{2 n} \\ \vdots & \vdots & \ldots & \vdots \\ 1 / a_{1 n} & 1 / a_{2 n} & \ldots & 1\end{array}\right]$
For the relative weight among factors, the eigenvalue solution in numerical analyses could be utilized for the maximum eigenvalue and the correspondent eigenvector.

According to AHP, pair comparison should satisfy the transitivity of preference and strength. Nevertheless, the actual evaluation could hardly satisfy such a hypothesis. Saaty therefore considered consistency tests for pair evaluation, including the steps of

1) Calculating Consistency Index (C.I.)

$$
\text { C.I. }=\frac{\lambda_{\max }-n}{n-1} ;
$$

2) Calculation Consistency Ratio (C.R.)

$$
\text { C.R. }=\frac{C . I .}{\text { R.I. }},
$$

where $\lambda_{\max }$ is the maximum eigenvalue of the matrix, $n$ is the matrix rank, and R.I. (Random Index) is the consistency index of the random matrix. R.I. value is related to the matrix level that the correspondent R.I. values could be found on the matrix level (Table 3 ).

Saaty [10] regarded the comparison being randomly generated when C.R. approached 1 and the consistency being higher when C.R. approached 0. In general, C.R. $\leq$ 0.1 was considered acceptable, while $C . R$. $>0.1$ showed the inconsistency that they had to be re-compared. After calculating the weight among factors in the hierarchies, the weight of the overall hierarchy should also be calculated.

\subsection{Map Overlaying Analysis in Geographic Information Systems}

Map overlaying is regarded as the major operation in analyzing the environmental features for regional planning [11]. Basically, it classifies various environmental factors by space distribution characteristics and proceeds overlaying with evaluations. When computer technology was rapidly progressed in 1970s, it gradually replaced manually map overlaying and reduced time consuming and human errors. Geographic information systems developed for distinct purposes rapidly grew in 1980s that the map overlaying analysis became one of the functions

Table 1. The meaning and description of scales for pair comparison with AHP (source: Saaty, 1990 [10]).

\begin{tabular}{lll}
\hline Scale & Definition & Description \\
\hline 1 & Equally important & The contribution of the two factors is equally important. \\
3 & Slightly important & Experiences and judgment slightly tend to certain factor. \\
5 & Quite important & Experiences and judgment strongly tend to certain factor. \\
7 & Extremely important & Experiences and judgment extremely strongly tend to certain factor. \\
9 & Absolutely important & There is sufficient evidence for absolutely tending to certain factor. \\
$2,4,6,8$ & The median between two neighboring scales & In between two judgments \\
\hline
\end{tabular}


Table 2. Questionnaire example of pair comparison in AHP.

\begin{tabular}{|c|c|c|c|c|c|c|c|c|c|c|c|c|c|c|c|c|c|}
\hline \multicolumn{9}{|c|}{ More important on the left } & \multicolumn{9}{|c|}{ More important on the right } \\
\hline \multicolumn{8}{|c|}{ Extent } & & \multicolumn{9}{|c|}{ Extent } \\
\hline $\begin{array}{c}\text { Absolutely } \\
\text { important }\end{array}$ & & $\begin{array}{l}\text { Extremely } \\
\text { important }\end{array}$ & & $\begin{array}{c}\text { Quite } \\
\text { important }\end{array}$ & & $\begin{array}{l}\text { Slightly } \\
\text { important }\end{array}$ & & $\begin{array}{l}\text { Equally } \\
\text { important }\end{array}$ & & $\begin{array}{l}\text { Slightly } \\
\text { important }\end{array}$ & & $\begin{array}{c}\text { Quite } \\
\text { important }\end{array}$ & & $\begin{array}{l}\text { Extremely } \\
\text { important }\end{array}$ & & $\begin{array}{l}\text { Absolutely } \\
\text { important }\end{array}$ & \\
\hline $9: 1$ & $8: 1$ & $7: 1$ & $6: 1$ & $5: 1$ & $4: 1$ & $3: 1$ & $2: 1$ & $1: 1$ & $1: 2$ & $1: 3$ & $1: 4$ & $1: 5$ & $1: 6$ & $1: 7$ & $1: 8$ & $1: 9$ & \\
\hline A & & & & & & & & & & & & & & & & & B \\
\hline
\end{tabular}

Table 3. Random Index value (source: Saaty, 1990 [10]).

\begin{tabular}{cccccccccccc}
\hline Rank & 1 & 2 & 3 & 4 & 5 & 6 & 7 & 8 & 9 & 10 \\
\hline R.I. & 0.00 & 0.00 & 0.58 & 0.90 & 1.12 & 1.24 & 1.32 & 1.41 & 1.45 & 1.49 \\
\hline
\end{tabular}

in geographic information systems [12,13]. After the expert questionnaire survey and AHP for weight of attributes, the maps collected by the map overlaying in GIS were overlaid for evaluations. The weighted linear combination analysis [4] was applied using the following equation:

$$
\text { E.R. }=\sum w_{i} x_{i}
$$

where E.R. is the environmental risk, $w_{i}$ is a weighting factor $i$ which is decided by AHP, and $x_{i}$ is the criterion score of factor $i$. The next section will illustrate the score estimations of each factor $i$ and application of potential hazard map overlaying in geographic information systems in details.

\section{Results and Discussions}

\subsection{Expert Questionnaire Design}

The questionnaire survey contained two parts [14]. The first part aimed to confirm the evaluated factors in compound potential hazard analysis. Having integrated several literatures review, the preliminary factor structure for compound potential hazard analysis was drawn as Table 4. The second part tended to evaluate the relative importance among evaluated items so as to determine the hierarchic matrix in analytic hierarchy process (AHP) for final weights.

The questionnaire survey was divided into two stages for clarifying the relationship among the factors. Expert questionnaire survey, as the first stage, aimed to ensure the importance priority of factors in compound potential hazard analysis. 0 - 10 levels were utilized that the higher score was obtained, the more importance it would present. The results could become the reference for expert evaluations in the second stage. Total 10 expert questionnaires were collected. The experts were specialized in civil and hydraulic engineering, architecture, urban planning, and soil and water conservation. Seven of them appeared more than 10 years working experiences.

In the second stage, the experts compared the relative importance of the paired factors for the comparison matrices in various hierarchies, Tables 5-8. Meanwhile, the weights of the evaluated items in Hierarchy II in Table 5 were multiplied by the weights of the factors in Hierarchy III in Tables 6-8 for the weights of the final factors, Table 9. From Table 9, Slope in Environmental geology presented the highest weight, Flood potential appeared the highest weight in Natural disaster, and Land use zoning showed the highest weight in Land use. In this case, the hierarchic analysis of expert questionnaires could select the major items in Compound potential hazard analysis by weights.

\subsection{Map Overlaying Criteria in GIS}

Aiming at drawing the $40 \mathrm{~m} \times 40 \mathrm{~m}$ grids around Changhua City in Taiwan, Figure 1, the criteria of Environmental geology, Natural disaster, and Land use acquired from expert questionnaires were proceeded map overlaying analyses in GIS for the values of grids. The weights acquired by AHP were applied to calculating the environmental risk in grids for compound potential hazard analysis. The descriptions of the criteria are showed as below.

As to Environmental geology criteria, environmental geology contained the items of Active faults, Active faults, Rock strength, Geological condition, and Slope. Each item has been classified as high, medium, and low risk of scores 3, 2, and 1, respectively. Table 10 indicates the criteria descriptions.

Similarity, Natural disaster criteria includes Landslide potential score, Debris flow potential score, and Flood potential score. For landslide potential, the data analyses utilized the environmental geology database maps of the urban and the surrounding slopes in Central Geological Survey (CGS) in Taiwan, in which Landslide potential was based for divisions. Meanwhile, the debris flow potential streams and the influential areas announced by Soil and Water Conservation Bureau (SWCB), Taiwan was utilized for data analyses, in which debris flow potential was based for divisions. The landslide and debris 
Table 4. Hierarchic structure of evaluated items in compound potential hazard analysis.

\begin{tabular}{ccc}
\hline Hierarchy I: Objective & Hierarchy II: Evaluated items & Hierarchy III: Factors \\
\hline & & Active faults \\
Rock strength \\
Geological condition \\
Slope \\
Compound potential hazard analysis & Landslide potential & Debris flow potential \\
Flood potential & Vegetation cover \\
Hatural disasters & & Human development \\
\hline
\end{tabular}

Table 5. Relative importance of evaluated items in Hierarchy II.

\begin{tabular}{ccccc}
\hline Hierarchic matrix & Environmental geology & Natural disaster & Land use & Weight \\
\hline Environmental geology & 1 & 0.1740 & 0.2387 & $9.08 \%$ \\
Natural disaster & 5.7471 & 1 & 0.4673 & $36.45 \%$ \\
Land use & 4.1894 & 2.1400 & 1 & $54.47 \%$ \\
\hline
\end{tabular}

Note: $\lambda_{\max }=3.42 ;$ C.I. $=0.210 ;$ C.R. $=0.112$.

Table 6. Relative importance of the factors in Environmental geology.

\begin{tabular}{cccccc}
\hline Hierarchic matrix & Active faults & Rock strength & Geological condition & Slope & Weight \\
\hline Active faults & 1 & 0.2075 & 0.2197 & 0.1839 & $5.80 \%$ \\
Rock strength & 4.8204 & 1 & 0.2677 & 0.3281 & $15.85 \%$ \\
Geological condition & 4.5509 & 3.7356 & 1 & 0.4884 & $33.06 \%$ \\
Slope & 5.4371 & 3.0476 & 2.0477 & 1 & $45.29 \%$ \\
\hline
\end{tabular}

Note: $\lambda_{\max }=4.26 ; C . I .=0.086 ; C . R .=0.095$.

Table 7. Relative importance of the factors in Natural disaster.

\begin{tabular}{ccccc}
\hline Hierarchic matrix & Landslide potential & Debris flow potential & Flood potential & Weight \\
\hline Landslide potential & 1 & 0.5119 & 0.3769 & $17.48 \%$ \\
Debris flow potential & 1.9537 & 1 & 0.5173 & $30.36 \%$ \\
Flood potential & 2.6531 & 1.9332 & 1 & $52.17 \%$ \\
\hline
\end{tabular}

Note: $\lambda_{\max }=3.01 ;$ C.I. $=0.007 ;$ C.R. $=0.012$.

Table 8. Relative importance of factors in Land use.

\begin{tabular}{cccc}
\hline Hierarchic matrix & Vegetation cover & Human development & Land use zoning \\
\hline Vegetation cover & 1 & 0.2889 & 0.3188 \\
Human development & 3.4615 & 1 & 0.4 \\
Land use zoning & 3.1366 & 2.5 & $31.37 \%$ \\
\hline
\end{tabular}

Note: $\lambda_{\max }=3.12 ;$ C.I. $=0.058 ;$ C.R. $=0.100$. 
Table 9. Weights of evaluated factors in Analytic Hierarchy Process (AHP).

\begin{tabular}{|c|c|c|c|}
\hline Hierarchy I: Objective & Hierarchy II: Evaluated items & Hierarchy III: Factors & Weight \\
\hline \multirow{10}{*}{ Compound potential hazard analysis } & \multirow{4}{*}{ Environmental geology } & Active faults & $0.53 \%$ \\
\hline & & Rock condition & $1.44 \%$ \\
\hline & & Geological condition & $3.00 \%$ \\
\hline & & Slope & $4.11 \%$ \\
\hline & \multirow{3}{*}{ Natural disaster } & Landslide potential & $6.37 \%$ \\
\hline & & Debris flow potential & $11.06 \%$ \\
\hline & & Flood potential & $19.01 \%$ \\
\hline & \multirow{3}{*}{ Land use } & Vegetation cover & $6.92 \%$ \\
\hline & & Human development & $17.09 \%$ \\
\hline & & Land use zoning & $30.46 \%$ \\
\hline
\end{tabular}

Table 10. The descriptions of the criteria score.

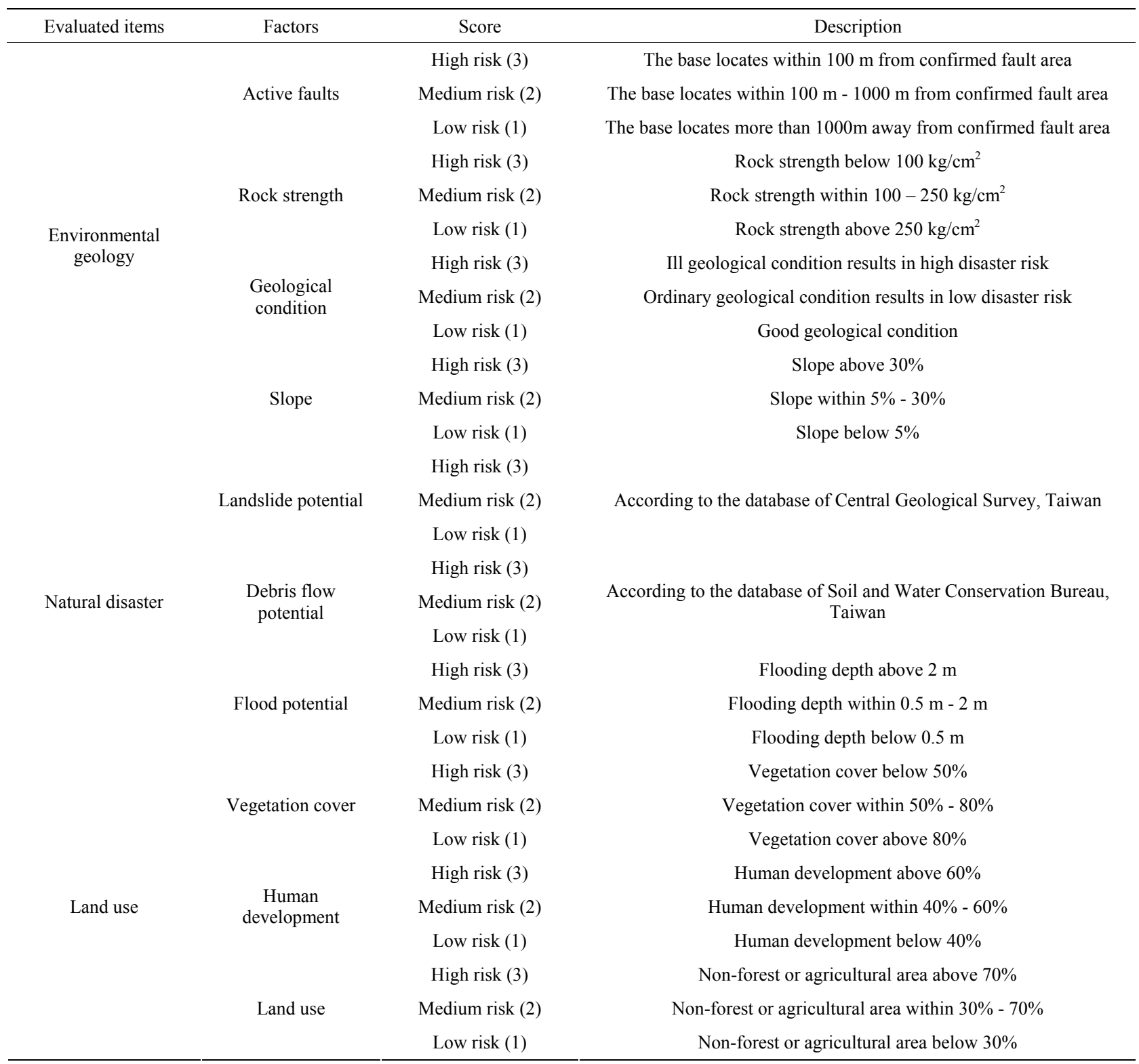


flow potential risk intensities were defined by CGS and SWCB, as to abide by the definitions of this research. The flooding areas were also utilized when the accumulated rainfall achieving $600 \mathrm{~mm}$, announced by Water Resources Agency, Taiwan for data analyses, in which the flooding depth was applied to analyses in Table 10.

This study utilized the results of national land survey by National Land Surveying and Mapping Center, Taiwan in 2007 for analyzing the criteria of the Land use. Based on the types of land use to determine the relevant indices, the area corresponding to the items in the $40 \mathrm{~m}$ grid was calculated. According to the percentage of the grid in the total area, three levels were divided for risk evaluation. Vegetation cover score, Human development score, and Land use score were obtained by analyzing the ratio of Vegetation cover area, Human development area, and Non-forest or agricultural areas in the $40 \mathrm{~m}$ grids, respectively, shown as in Table $\mathbf{1 0 .}$

\subsection{Outcomes of Map Overlaying Analyses in GIS}

Having Changhua City as the studied area, the north end of Baguashan is located on the south, Wu River is next to the east and the north, the west and the north areas are plain terrain, and the elevation is within $0 \mathrm{~m}-231.5 \mathrm{~m}$ (see Figure 1).

In the first step, consider the Environmental geology criteria. The result of Active faults score in the studied area covered Changhua fault through the plain in the west, was shown as Figure 2. As Rock strength score, Rock strength in the studied area was less than 100 $\mathrm{kg} / \mathrm{cm}^{2}$ that it was regarded as High risk area (Figure 3). Geological condition score in the studied area was considered ill Geological condition and it was regarded as the high disaster risk area, in Figure 4. The last score, Slope score, based on $5 \mathrm{~m} \times 5 \mathrm{~m}$ digital elevation model (DEM) to precede slope analyses, Figure 5, the average slope was $11.53 \%$, and most areas appeared 5\%.

The second step for Natural disaster criteria, there was no debris flow potential stream in the studied area, so the Debris flow potential risk was not considered. The landslide potential area in Figure 4 represented the score value 3 and the non-landslide area 1 for calculations. In Flood potential consideration, the flooding areas when the accumulated rainfall being $600 \mathrm{~mm}$, announced by Water Resources Agency in Taiwan, were utilized for data analyses. The flooding depth was the analysis criteria, shown in Figure 6. In the third step, Land use criteria, based on the results of the national land survey from $\mathrm{Na}$ tional Land Surveying and Mapping Center, Taiwan in 2007, Figure 7, the risk level (Figures 8-10) according to Figure $\mathbf{7}$ and Table 10 for Land use was evaluated.

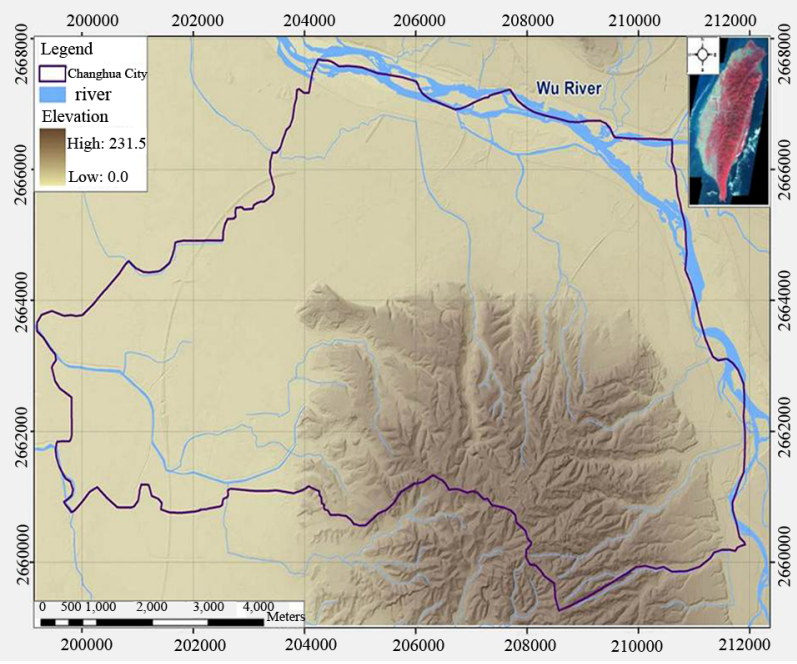

Figure 1. Topography of the studied area.



Figure 2. Active fault distribution in the studied area.

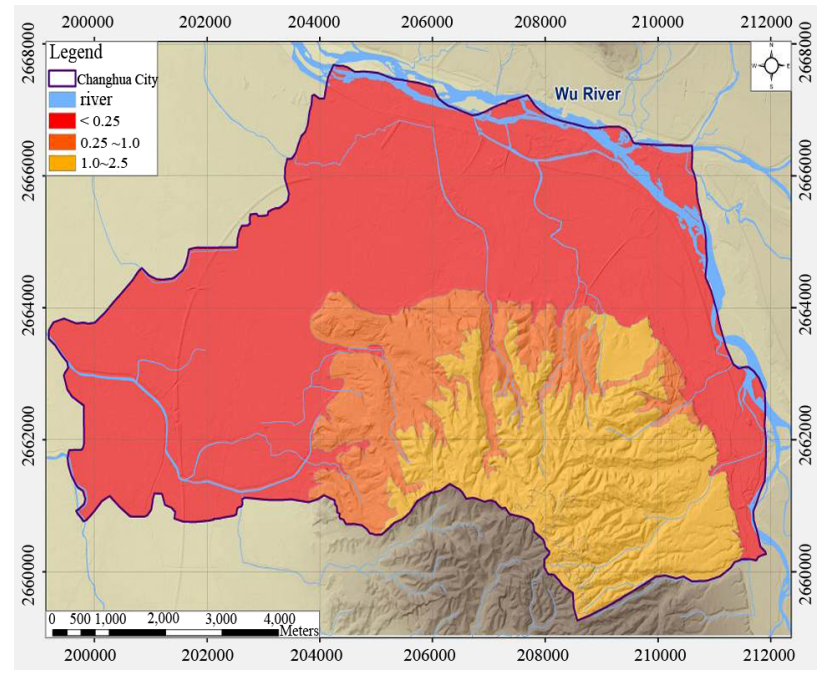

Figure 3. Rock strength distribution in the studied area. 


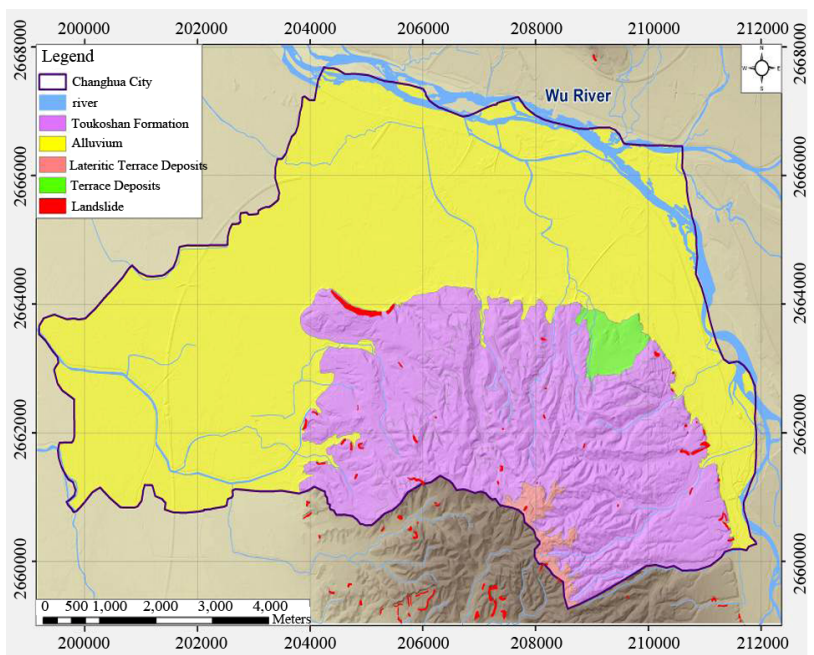

Figure 4. Geological condition and landslide potential distribution in the studied area.

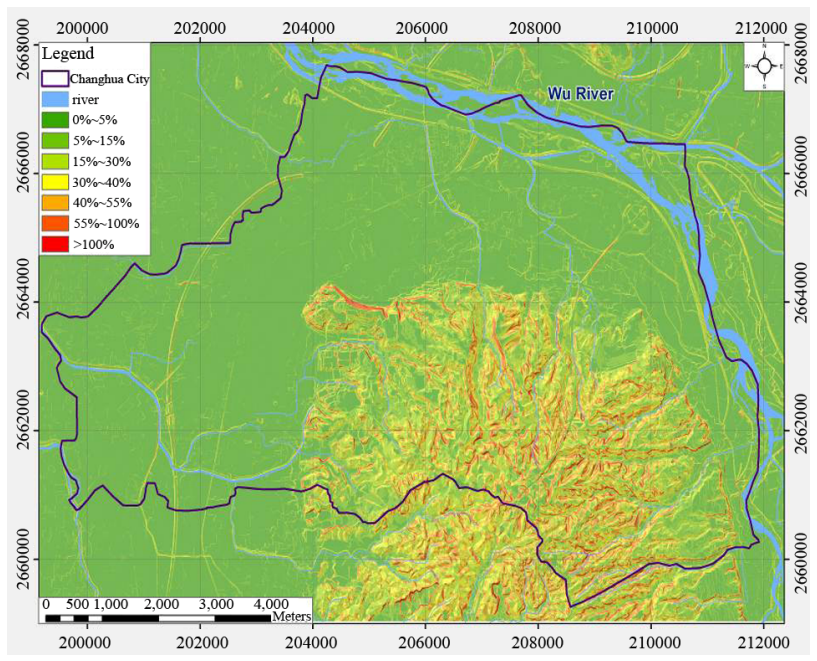

Figure 5. Slope distribution in the studied area.

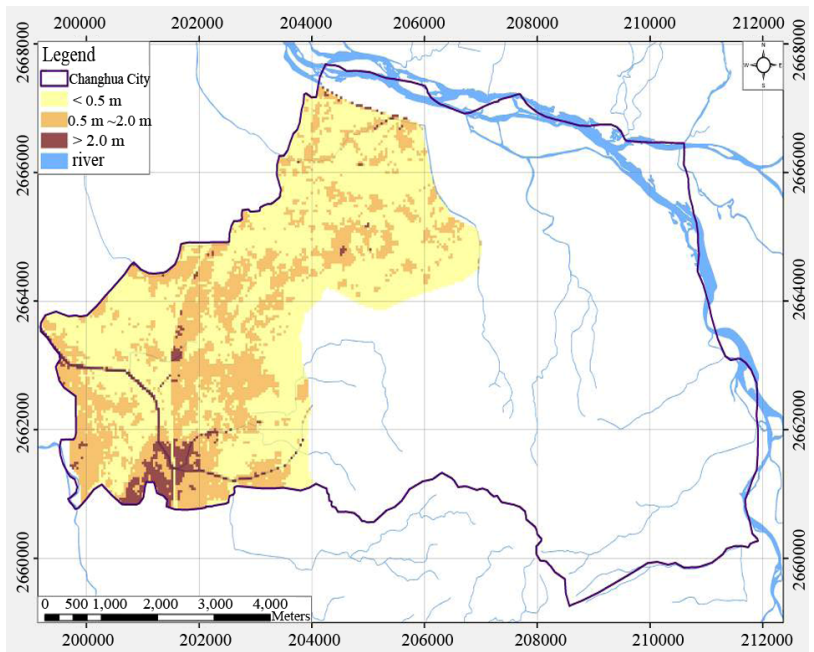

Figure 6. Flood potential distribution in the studied area with accumulated rainfall $600 \mathrm{~mm}$.

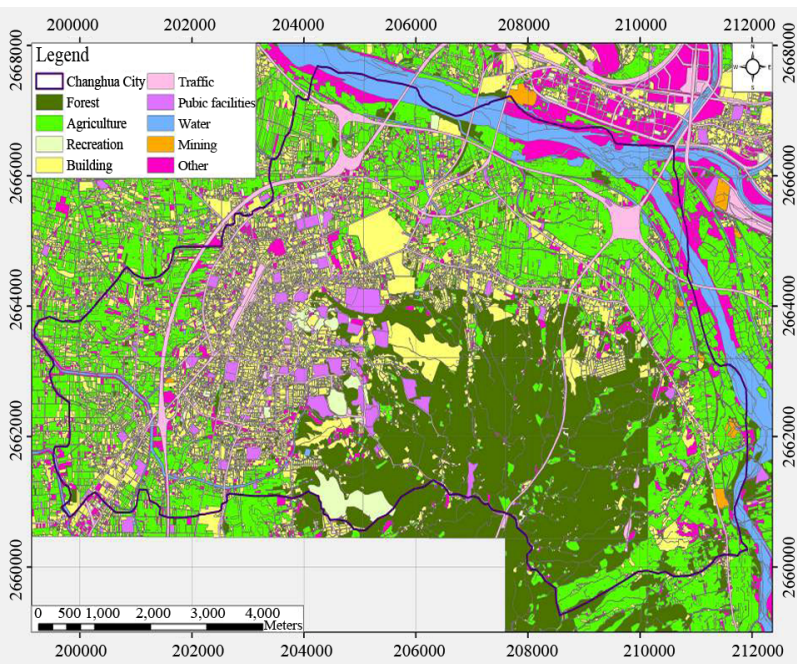

Figure 7. Land use distribution in the studied area.



Figure 8. Vegetation cover distribution in the studied area.

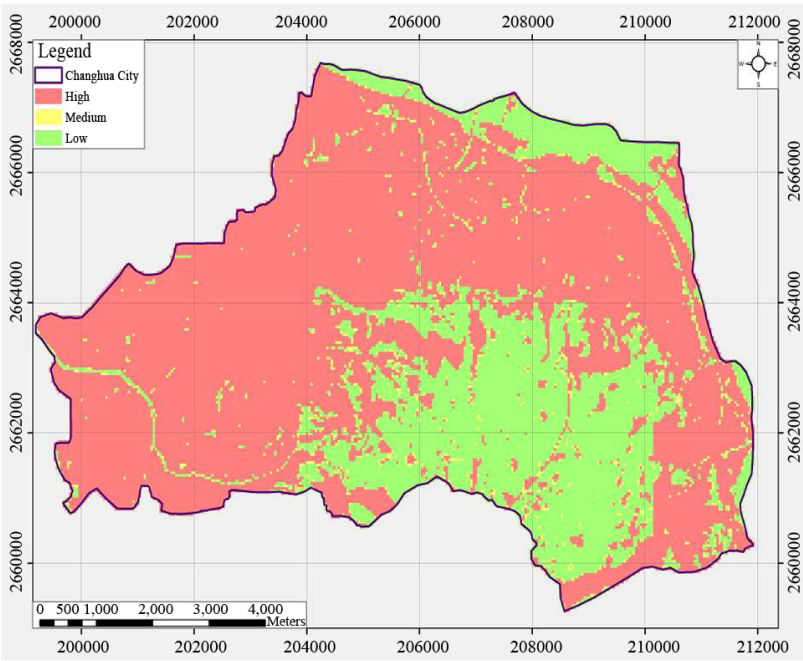

Figure 9. Human development distribution in the studied area. 


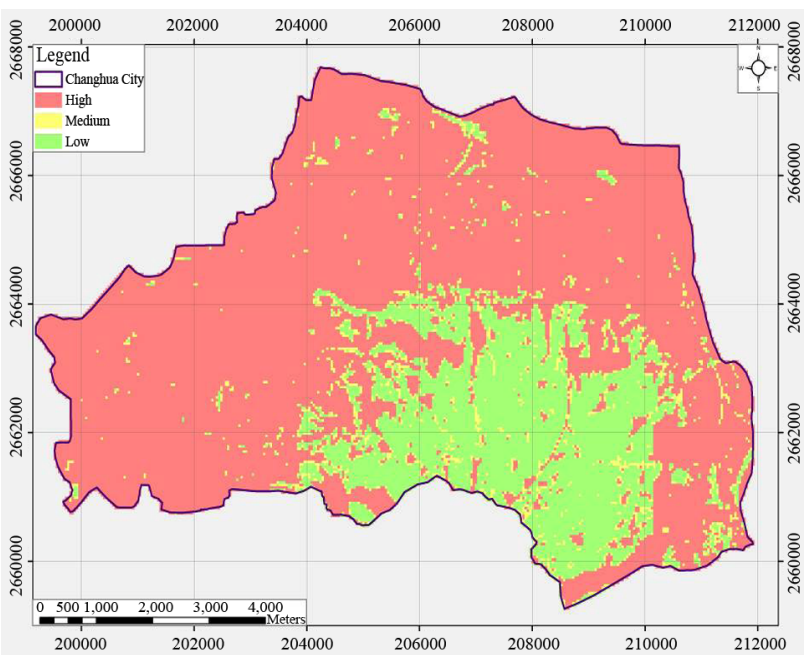

Figure 10. Land use distribution in the studied area.

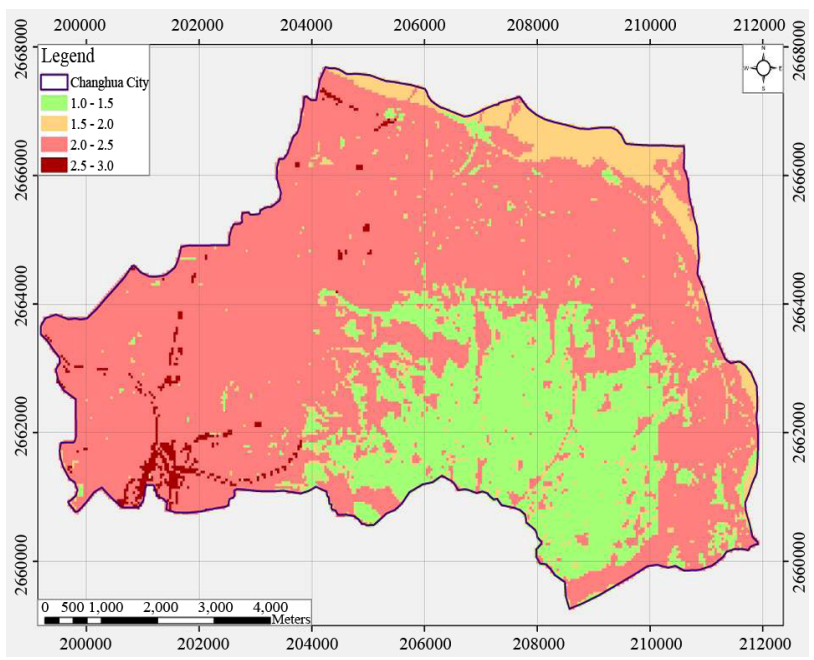

Figure 11. Environmental risk distribution in the studied area.

Finally, by summing up the weights in AHP, the Environmental Risk in the grids was calculated, Figure 11. Based on Tables 9 and 10, we obtained the Environmental Risk by the product of factors (Figures 2-10) and weightings (Table 9). Having considered the factors of Environmental geology, Natural disaster, and Land use, the results acquired from AHP and map overlaying in GIS presented that the higher score value was shown, the higher disaster potential would present, Figure 11. The reference of the results could be provided to those who have the relevant planning of researches.

\section{Conclusion}

With expert survey to formulate the weight analysis, various types of disasters were overlaid to form the compound potential hazard map. Traditional numerical simulation merely simulated single disaster $[15,16]$.
However, this study combines the present map information (including traditional numerical simulation results), expert questionnaires, and overlaying analyses in Geographic Information Systems, aiming to clarify the relationship among factors in compound potential hazard analysis. Based on the weights of factors from expert questionnaire analyses, more important evaluated items were selected. Such results could provide reference for the personnel related to disaster prevention. Moreover, the future security evaluation for hideout points and evacuation routes and the development of geographic information systems could also base on the results.

\section{Acknowledgements}

This research was supported in part by grants from Chienkuo Technology University (CTU-101-RP-SD-001016-A).

\section{REFERENCES}

[1] Water Resources Agency, "Hydrological Analysis Report of Typhoon Morakot," Presentation Document of Water Resources Agency, Ministry of Economic Affairs, Taiwan, 2009 (in Chinese).

[2] S. C. Chen, J. W. Ferng, Y. T. Wang, T. Y. Wu and J. J. Wang, "Assessment of Disaster Resilience Capacity of Hillslope Communities with High Risk for Geological Hazards," Engineering Geology, Vol. 98, No. 3-4, 2008, pp. 86-101. doi:10.1016/j.enggeo.2008.01.008

[3] F. Guzzetti, F. Ardizzone, M. Cardinali, M. Galli, P. Reichenbach and M. Rossi, "Distribution of Landslides in the Upper Tiber River Basin, Central Italy," Geomorphology, Vol. 96, No. 1-2, 2008, pp. 105-122. doi:10.1016/j.geomorph.2007.07.015

[4] A. Al-Hanbali, B. Alsaaideh and A. Kondoh, "Using GIS-Based Weighted Linear Combination Analysis and Remote Sensing Techniques to Select Optimum Solid Waste Disposal Sites within Mafraq City, Jordan," Journal of Geographic Information System, Vol. 3 No. 4, 2011, pp. 267-278. doi:10.4236/jgis.2011.34023

[5] R. Raaijmakers, J. Krywkow and A. van der Veen, "Flood Risk Perceptions and Spatial Multi-Criteria Analysis: An Exploratory Research for Hazard Mitigation," Natural Hazards, Vol. 46, No. 3, 2008, pp. 307-322. doi:10.1007/s11069-007-9189-z

[6] S. Karmakar, S. Simonovic, A. Peck and J. Black, "An Information System for Risk-Vulnerability Assessment to Flood," Journal of Geographic Information System, Vol. 2, No. 3, 2010, pp. 129-146. doi:10.4236/jgis.2010.23020

[7] H. de Moel and J. C. J. H. Aerts, "Effect of Uncertainty in Land Use, Damage Models and Inundation Depth on Flood Damage Estimates," Natural Hazards, Vol. 58, No. 1, 2011, pp. 407-425. doi:10.1007/s11069-010-9675-6

[8] A. Gharagozlou, H. Nazari and M. Seddighi, "Spatial Analysis for Flood Control by Using Environmental 
Modeling," Journal of Geographic Information System, Vol. 3, No. 4, 2011, pp. 367-372.

doi:10.4236/jgis.2011.34035

[9] T. L. Saaty, "The Analytic Hierarchy Process," McGrawHill Press, New York, 1980.

[10] T. L. Saaty, "Decision Making for Leaders-The Analytic Hierarchy Process for Decisions in a Complex World," RWS Publications Press, Pittsburgh, 1990.

[11] F. Steiner, "The Living Landscape: An Ecological Approach to Landscape Planning," McGraw-Hill Press, New York, 2000.

[12] Y. Meng, J. Malczewski and S. Boroushaki, "A GISBased Multicriteria Decision Analysis Approach for Mapping Accessibility Patterns of Housing Development Sites: A Case Study in Canmore, Alberta," Journal of Geographic Information System, Vol. 3, No. 1, 2011, pp. 5061. doi:10.4236/jgis.2011.31004

[13] K. Bhattarai and D. Conway, "Urban Vulnerabilities in the Kathmandu Valley, Nepal: Visualizations of $\mathrm{Hu}-$
man/Hazard Interactions," Journal of Geographic Information System, Vol. 2, No. 2, 2010, pp. 63-84. doi:10.4236/jgis.2010.22012

[14] D. Nevo and Y. E. Chan, "A Delphi Study of Knowledge Management Systems: Scope and Requirements," Information \& Management, Vol. 44, No. 6, 2007, pp. 583597. doi:10.1016/j.im.2007.06.001

[15] R. Garcia, J. L. López, M. Noya, M. E. Bello, M. T. Bello, N. González, G. Paredes, M. I. Vivas and J. S. O’Brien, "Hazard Mapping for Debris Flow Events in the Alluvial Fans of Northern Venezuela," In: D. Rickenmann and C. Chen, Eds., Proceedings of the 3rd International Conference on Debris-Flow Hazards Mitigation: Mechanics, Prediction and Assessment, China Geological Library, Beijing, 2003, pp. 589-599.

[16] R. Garcia and J. L. Lopez, "Debris Flows of December 1999 in Venezuela," In: M. Jakob and O. Hungr, Eds., Debris-Flow Hazards and Related Phenomena, Springer Verlag Praxis, Berlin, 2005, pp. 519-538. 